\title{
o mito do referencial ${ }^{*(* *)}$
}

\section{Karl R. Popper}

\begin{abstract}
"Aqueles que acreditam nisso e aqueles que $\mathrm{n}$ o o fazem $n$ o $t$ m uma base comum de discuss o, mas em face de suas opini es devem necessariamente desprezar uns aos outros."
\end{abstract}

PLAT O

UM DOS TRAÇOS MAIS Perturbadores da vida intelectual da atualidade é a maneira como se defende $t$ o amplamente o irracionalismo e se admitem doutrinas irracionalistas. A meu ver, um dos principais componentes do irracionalismo moderno é o relativismo (a doutrina de que a verdade é relativa a nosso referencial ou formaç o intelectual: que ela pode mudar de um referencial para outro) e, em particular, a doutrina da impossibilidade de um mútuo entendimento entre diferentes culturas, geraç es ou per odos históricos. Discuto no presente texto o problema do relativismo; alego que por trás dele está o que chamo de "o mito do referencial". Explico e critico esse mito e também comento argumentos que t $m$ sido usados em sua defesa que se devem a Quine, Kuhn e Whorf.

Os proponentes do relativismo colocam diante de nós padr es de entendimento mútuo que s o irrealisticamente elevados; e, quando n o 
conseguimos satisfazer esses padr es, sustentam que o entendimento é imposs vel. Contra isso, argumento que, se se investir bastante esforço e boa-vontade comum, ent o é poss vel um entendimento de alcance bem amplo. Ademais, o esforço é amplamente recompensado pelo que aprendemos no processo acerca de nossos próprios pontos de vista, como também acerca daqueles que nos dispomos a entender.

Este texto pretende desafiar o relativismo em seu sentido mais amplo. É importante apresentar tal desafio, pois hoje em dia a crescente escalada na produç o de armas tem feito a sobreviv ncia quase id ntica ao entendimento.

\section{II}

Embora seja admirador da tradiç o, sou ao mesmo tempo adepto quase ortodoxo da heterodoxia: sustento que a ortodoxia é a morte do conhecimento, uma vez que o desenvolvimento do conhecimento depende inteiramente da exist ncia de discord ncias. Deve-se reconhecer que a discord ncia pode levar contenda e até viol ncia; e penso eu que isto é de fato muito ruim, pois detesto a viol ncia. A discord ncia, todavia, pode também levar discuss o, argumentaç o- cr tica mútua - e penso que isso é de import ncia suprema. Sugiro que o passo mais largo em direç o a um mundo melhor e mais pac fico deu-se quando a guerra de espadas começou a ser sustentada, e s vezes mesmo substitu da, por uma guerra de palavras. É por isso que meu tema tem import ncia prática.

Mas primeiro explicarei qual é o meu tema e o que quero dizer com meu t tulo "O Mito do Referencial". Discutirei e argumentarei contra um mito - uma falsa história que é amplamente aceita, em especial na Alemanha. De lá ele invadiu os Estados Unidos, onde tornou-se muito difundido. Assim, receio que a maioria de meus leitores de agora possa acreditar nele, consciente ou inconscientemente. $\mathrm{O}$ mito do referencial pode ser enunciado na seguinte sentença:

Uma discuss o racional e frut fera é imposs vel a menos que os participantes compartilhem um referencial comum de pressupostos básicos, ou que, pelo menos, concordem acerca de um tal referencial para fim de discuss o. 


\section{Este o mito que me proponho a criticar.}

Tal como o formulei, o mito soa como um enunciado sensato, ou como uma judiciosa advert ncia qual devemos prestar atenç o para promover uma discuss o racional. Algumas pessoas pensam mesmo que é um princ pio lógico, ou baseado num princ pio lógico. Ao contrário, penso que ele é $\mathrm{n}$ o apenas um enunciado falso, mas também um enunciado vicioso que, se amplamente aceito, irá solapar a unidade da humanidade e aumentar muito a probabilidade da viol ncia e da guerra. Esta é a raz o principal pela qual desejo combat -lo e refutá-lo.

Direi ao mesmo tempo que o mito contém um gr o de verdade. Embora eu sustente que é um grande exagero dizer que uma discuss o frut fera é imposs vel a menos que os participantes partilhem de um referencial comum, estou muito disposto a admitir que uma discuss o entre participantes que $\mathrm{n}$ o partilham de um referencial comum pode ser dif cil. Uma discuss o será também dif cil se os referenciais tiverem pouco em comum e será tanto mais fácil quanto maior a superposiç o entre os referenciais. Na verdade, se os participantes concordam em todos os pontos, ela se converterá freq entemente na mais fácil e mais suave discuss o poss vel - embora venha a ser provavelmente um pouco maçante.

Mas o que dizer de sua fecundidade? $\mathrm{Na}$ formulaç o que dei ao mito, o que se proclama imposs vel é uma discuss of frut fera. Contra isso defenderei a tese de que é improvável que uma discuss o entre pessoas que compartilham muitos pontos de vista seja frut fera, muito embora possam considerá-la agradável e altamente satisfatória, enquanto uma discuss o entre referenciais amplamente diferentes pode ser extremamente frut fera, muito embora venha a ser normalmente dif cil e talvez $\mathrm{n}$ o inteiramente agradável (embora possamos aprender a apreciá-la).

Penso que podemos dizer de uma discuss o que ela foi tanto mais frut fera quanto mais seus participantes aprenderam com ela. E isso significa: quanto mais quest es interessantes e dif ceis tenham feito, quanto mais novas respostas tenham sido induzidos a pensar, quanto mais tenham sido abalados em suas opini es e quanto mais coisas diferentes possam ver depois da discuss o; em suma, quanto mais seu horizonte intelectual tenha sido ampliado.

A fecundidade, nesse sentido, dependerá quase sempre da dist ncia original entre as opini es dos participantes da discuss o. Quanto maior 
a dist ncia, tanto mais pode a discuss o ser frut fera - sempre, naturalmente, desde que uma tal discuss o n o seja completamente imposs vel, como afirma o mito do referencial.

\section{III}

Mas ela é imposs vel? Tomemos um caso extremo. Heródoto narra uma história muito interessante, embora um tanto horripilante, sobre o rei persa Dario I, que queria ensinar uma liç o aos gregos que residiam na Pérsia, cujo costume era cremar seus mortos. Lemos em Heródoto que ele "convocou os gregos que viviam em sua terra e lhes perguntou mediante que pagamento consentiriam em devorar seus ancestrais quando morressem. Eles responderam que nada na terra os induziria a fazer isso. Ent o Dario convocou os (...) calatianos, que costumam comer seus ancestrais mortos, e lhes perguntou, na presença dos gregos, que tinham a ajuda de um intérprete, mediante que pagamento consentiriam eles em cremar os corpos de seus ancestrais quando morressem. E eles se lamentaram em voz alta e lhe imploraram que n o mencionasse uma tal abominaç o."1

Suspeito que Dario quis demonstrar a verdade do mito do referencial. Realmente, nos é dado entender que uma discuss o entre as duas partes teria sido imposs vel mesmo com a ajuda do intérprete. Foi um caso extremo de uma "confrontaç o" - para usar uma palavra muito em voga entre os que cr em na verdade do mito e uma palavra que gostam de usar quando desejam chamar nossa atenç o para o fato de que uma confrontaç o raramente resulta numa discuss o frut fera.

Mas supondo que essa confrontaç o encenada pelo rei Dario ocorreu, foi ela realmente infrut fera? Eu o nego. Pode haver pouca dúvida que as duas partes ficaram profundamente abaladas pela experi ncia. Eu mesmo acho a idéia do canibalismo t o revoltante como o foi para os gregos na corte do rei Dario e suponho que meus leitores sentir o o mesmo. Mas esses sentimentos devem nos fazer a todos mais perceptivos e mais gratos pela admirável liç o que Heródoto deseja extrair da história. Aludindo distinç o de $\mathrm{P}$ ndaro entre natureza e convenç $\mathrm{o},{ }^{2}$ Heródoto sugere 
que dever amos considerar com toler ncia e mesmo com respeito costumes ou leis consuetudinárias que diferem de nossas próprias convenç es. Se esta confrontaç o particular realmente ocorreu, alguns dos participantes bem podem ter reagido a ela da maneira ilustrada com que Heródoto deseja que reajamos sua história.

Isso mostra que há uma possibilidade de uma confrontaç o frut fera, mesmo sem uma discuss o, entre pessoas profundamente comprometidas com referenciais diferentes. Naturalmente, $n$ o devemos esperar demais: $n$ o devemos esperar que uma confrontaç o, ou mesmo uma prolongada discuss o, venha a terminar com os participantes alcançando acordo.

Mas um acordo é sempre desejável? Vamos supor que haja uma discuss o e que o assunto em quest o seja a verdade ou falsidade de alguma teoria ou hipótese. Nós - isto é, os juizes ou testemunhas racionais da discuss o-gostar amos naturalmente que a discuss o conclu sse com todas as partes concordando que a teoria é verdadeira se de fato é verdadeira, ou que a teoria é falsa se de fato é falsa: gostar amos que a discuss o alcançasse, se poss vel, um veredicto verdadeiro. Mas n o gostar amos da idéia de que foi alcançado acordo acerca da verdade da teoria se a teoria era de fato falsa; e mesmo se fosse verdadeira, preferir amos que $\mathrm{n}$ o fosse alcançado nenhum acordo sobre sua verdade se os argumentos que apóiam a teoria forem demasiado fracos para permitir sustentar a conclus o. Em tal caso preferimos que $\mathrm{n}$ o se tenha conseguido acordo. E em tal caso dir amos que a discuss o foi frut fera quando o choque de opini es levou os participantes a produzirem novos e interessantes argumentos, ainda que esses argumentos fossem inconclusivos. Pois argumentos conclusivos s o muito raros em todos os assuntos, exceto os mais triviais, ainda que argumentos contra uma teoria possam ser s vezes razoavelmente fortes.

Relembrando a história da confrontaç o contada por Heródoto, podemos ver agora que, mesmo nesse caso extremo em que nenhum acordo estava vista, a confrontaç o pode ter sido útil, e que, havendo tempo e paci ncia-o que Heródoto parece ter tido sua disposiç o-a confrontaç o produziu fruto, ao menos na mente do próprio Heródoto. 


\section{IV}

Desejo agora sugerir que, de certo modo, nós próprios somos e nossas atitudes s o os resultados de confrontaç es e de discuss es inconclusivas desta espécie.

$\mathrm{O}$ que quero dizer pode ser resumido pela tese de que nossa civilizaç o ocidental é o resultado do choque, ou da confrontaç o, de diferentes culturas, e portanto da confrontaç o de referenciais.

Admite-se geralmente que nossa civilizaç o - que, no melhor dos casos, pode ser descrita, um tanto eufemisticamente, como uma civilizaç o racionalista - é em grande parte o resultado da civilizaç o greco-romana. Ela adquiriu muitas de suas caracter sticas, tais como o alfabeto e o cristianismo, n o somente através de choques entre romanos e gregos, mas também através de seus choques com os judeus, os fen cios e outras civilizaç es do Oriente Médio e também através de choques devidos a invas es germ nicas e isl micas.

Mas o que dizer do original milagre grego - a origem da poesia, da arte, da filosofia e da ci ncia gregas; a origem real do racionalismo ocidental? Durante muitos anos tenho afirmado que o milagre grego, na medida em que pode ser explicado, deveu-se também em grande parte ao choque cultural. Parece-me que esta é na verdade uma das liç es que Heródoto quer nos ensinar em sua Hist ria.

Lembremos por um momento da origem da filosofia grega. Tudo começou nas col nias gregas da Ásia Menor, no Sul da Itália e na Sic lia, isto é, lugares onde, no Oriente, os colonos gregos foram confrontados com grandes civilizaç es orientais e entraram em choque com elas, ou onde, no Ocidente, se encontraram com sicilianos, cartagineses e italianos, tais como os toscanos. O impacto do choque cultural sobre a filosofia grega é muito óbvio desde os mais antigos relatos sobre Tales. Isto é inequ voco em Heráclito. Mas a maneira pela qual isso leva os homens a pensarem criticamente aparece o mais vigorosamente em Xenófanes, o bardo itinerante. Embora eu tenha citado alguns de seus versos em outras ocasi es, fá-lo-ei de novo porque eles ilustram meu ponto de vista muito bem. ${ }^{3}$ 
Os et opes dizem que os deuses s o negros e de nariz chato,

Enquanto os tr cios dizem que os seus $t m$ os olbos azuis e os cabelos ruivos.

Todavia, se os bois, os cavalos ou os le es tivessem $m$ os e fossem capazes de pintar

$E$ de fazer esculturas como os homens, ent o os cavalos desenhariam seus deuses

Semelhantes a cavalos e os bois semelhantes a bois e cada um faria

Os corpos dos deuses semelhança, cada esp cie, do seu pr prio.

Os deuses $n$ o nos revelam desde o princ pio

Todas as coisas, mas no decorrer do tempo,

Mediante busca, podemos aprender e conbecer melhor as coisas...

Essas coisas, $n$ s conjeturamos, s o como a verdade.

Mas quanto verdade certa, nenhum homem a conbece

Nem ir conbec-la; nem quanto aos deuses,

Nem ainda quanto a todas as coisas de que falo.

E mesmo se por acaso fosse proferir

A verdade final, ele mesmo $n$ o o saberia:

Pois tudo apenas uma teia trançada de conjeturas.

Embora Burnet e outros o tenham negado, penso que Parm nides, talvez o maior desses pensadores antigos, sofreu influ ncia de Xenófanes. ${ }^{4}$ Ele aceitou a distinç o de Xenófanes entre uma verdade final que n o está sujeita convenç o humana e as conjeturas, ou opinies, e as convenç es dos mortais. Há sempre muitas convenç es e opini es conflitantes concernentes a qualquer problema ou assunto (tal como os deuses), o que mostra que elas n o s o todas verdadeiras, pois, se conflitam entre si, ent o, no melhor dos casos, somente uma delas pode ser verdadeira. ${ }^{5}$ Deste modo parece que Parm nides (um contempor neo de $\mathrm{P}$ ndaro, a quem Plat o atribui a distinç o entre natureza e convenç o) foi o primeiro a distinguir claramente entre verdade ou realidade, de um lado, e convenç o ou opini o convencional - suposiç o, mito plaus vel -, de outro; uma liç o que, pode-se dizer, ele recebeu de Xenófanes e do choque cultural. O que o conduziu a uma das mais arrojadas teorias jamais concebidas.

O papel desempenhado pelo choque cultural no surgimento da ci ncia grega - matemática e astronomia - é bem conhecido e pode-se até especificar a maneira pela qual os diversos choques renderam fruto. 
E nossas idéias de liberdade, democracia, toler ncia e também as idéias de conhecimento, ci ncia, racionalidade, pode-se remeter todas a essas origens.

De todas essas idéias, a de racionalidade parece-me a mais fundamental.

Pelo que sabemos a partir das fontes, a invenç o da discuss o racional ou cr tica parece ser contempor nea de alguns desses choques e a discuss o se tornou tradicional com o surgimento das primeiras democracias $j$ nicas.

\section{V}

Em sua aplicaç o ao problema do entendimento do nosso mundo, e assim ao surgimento da ci ncia, a racionalidade tem dois componentes que s o de import ncia aproximadamente igual.

O primeiro é a inventividade poética, isto é, o fato de se contar histórias ou de se criar mitos: a invenç o de histórias que explicam o mundo. Estas s o, antes de tudo, amiúde ou talvez sempre polite stas. Os homens sentem que est $\mathrm{o}$ nas $\mathrm{m}$ os de forças desconhecidas e tentam entender $\mathrm{e}$ explicar o mundo e a vida humana e a morte inventando histórias ou mitos a respeito dessas forças.

Esse primeiro componente, que talvez possa ser $\mathrm{t}$ o antigo quanto a própria linguagem humana, é absolutamente importante e parece universal: todas as tribos, todos os povos, $\mathrm{t}$ m tais histórias explicativas, amiúde na forma de contos de fadas. Parece que a invenç o de explicaç es e histórias explicativas é uma das funç es básicas da linguagem humana.

O segundo componente é de época comparativamente recente. Parece que é especificamente grego e teria surgido depois do estabelecimento da escrita na Grécia. Parece que surgiu com Anaximandro, o segundo filósofo j nico. É a invenç o da cr tica, da discuss o cr tica dos diversos mitos explicativos, com o propósito de aperfeiçoá-los conscientemente.

O principal exemplo grego de criaç o de mitos explicativos em escala elaborada é, naturalmente, a Teogonia de Hes odo. Esta é uma his- 
tória fantástica da origem e das boas e más aç es dos deuses gregos. Dificilmente alguém se sentiria inclinado a considerar que a Teogonia proporciona uma sugest o que possa ser usada no desenvolvimento de uma explicaç o cient fica do mundo. Apesar disso, propus a conjetura histórica de que uma passagem da Teogonia ${ }^{6}$ de Hes odo, que foi antecipada por outra passagem da $\mathrm{Il} a d a^{7}$ de Homero, foi assim usada por Anaximandro, o primeiro cosmólogo cr tico.

Explicarei minha conjetura. De acordo com a tradiç o, Tales, professor e parente de Anaximandro e fundador da escola j nica de cosmólogos, ensinava que "a terra é sustentada por água sobre a qual ela flutua como um navio". Anaximandro, disc pulo, parente e sucessor de Tales, desviou-se deste mito um tanto ing nuo (com o qual Tales tencionava explicar terremotos). O novo ponto de partida de Anaximandro teve um caráter verdadeiramente revolucionário, pois nos é dito que ele ensinava o seguinte: "N o há absolutamente nada que esteja sustentando a terra. Ao invés, a terra permanece estacionária devido ao fato de que está igualmente distante de todas as outras coisas. Sua forma assemelha-se de um tambor. Nós andamos sobre uma de suas superf cies planas, enquanto a outra está do lado oposto."

Esta idéia audaciosa tornou poss vel as idéias de Aristarco e Copérnico e contém mesmo uma antecipaç o das forças de Newton. Como ela surgiu? Propus a conjetura ${ }^{8}$ de que ela surgiu de uma cr tica puramente lógica do mito de Tales. A cr tica é simples: se resolvemos o problema da explicaç o da posiç o e da estabilidade da terra no universo dizendo que ela é sustentada pelo oceano, como um navio é sustentado pela água, n o somos ent o compelidos, indaga o cr tico, a levantar um novo problema, que é o da explicaç o da posiç o e da estabilidade do oceano? Mas isso significaria encontrar algum apoio para o oceano, e logo algum novo apoio para este apoio. Obviamente, isso conduz a uma regress o infinita. Como podemos evitá-la?

Procurando uma sa da desse impasse assustador que nenhuma explicaç o alternativa parecia capaz de evitar, conjeturo que Anaximandro recordou uma passagem em que Hes odo desenvolve uma idéia da Il ada onde nos é dito que o Tártaro está exatamente t o abaixo da Terra quanto Urano, ou o céu, está acima dela. 
A passagem é a seguinte: "Por nove noites e dias uma bigorna de bronze cairá do céu e só no décimo alcançará a terra. E por nove noites e dias uma bigorna de bronze cairá da terra e no décimo alcançará o Tártaro." ${ }^{9}$ Essa passagem pode ter sugerido a Anaximandro que podemos esboçar um diagrama do mundo, com a terra no meio e a abóbada celeste como um hemisfério acima dela. A simetria, ent o, sugere que interpretemos o Tártaro como sendo a metade inferior da abóbada. Dessa maneira chegamos construç o de Anaximandro tal como nos é transmitida; uma construç o que rompe o beco-sem-sa da da regress o infinita.

Penso que é preciso uma tal explicaç o conjetural do formidável passo que conduziu Anaximandro além de seu mestre Tales. Parece-me que minha conjetura torna o passo mais compreens vel e, ao mesmo tempo, até mais impressionante, pois agora ele é visto como uma soluç o racional de um problema muito dif cil - o problema do apoio e da estabilidade da terra.

Todavia, a cr tica de Anaximandro a Tales e sua construç o cr tica de um novo mito a nada teriam levado se $\mathrm{n}$ o tivessem tido seq ncia. Como podemos explicar o fato de que tiveram seq ncia? Por que um novo mito foi apresentado em cada geraç o depois de Tales? Tentei explicar isso pela posterior conjetura de que Tales e Anaximandro juntos fundaram a tradiç o de uma nova escola: - a tradiç o cr tica.

Minha tentativa de explicar o fen meno do racionalismo grego e da tradiç o cr tica grega por uma tradiç o de escola, naturalmente, é mais uma vez completamente conjetural. De fato, ela mesma é uma espécie de mito. Todavia, explica um fen meno único - a escola j nica. Essa escola, por pelo menos quatro ou cinco geraç es, produziu em cada nova geraç o uma engenhosa revis o dos ensinamentos da geraç o precedente. No fim, estabeleceu o que podemos chamar de tradiç o cient fica: uma tradiç o de cr tica que sobreviveu por pelo menos quinhentos anos e que sobreviveu, antes de sucumbir, a alguns sérios ataques.

A tradiç o cr tica é constitu da pela adoç o do método de criticar uma história ou explicaç o ortodoxa e em seguida obter uma história nova, melhorada, imaginativa, a qual, por sua vez, é submetida cr tica. Afirmo que este método é o método da ci ncia. Parece ter sido inventado apenas uma vez na história humana. Morreu no Ocidente quando as escolas de Atenas foram eliminadas por um cristianismo vitorioso e intolerante, embora tenha durado no Oriente. Foi pranteado durante a Idade Média. 
E foi n o tanto reinventado mas reimportado no Renascimento, juntamente com a redescoberta da filosofia grega e da ci ncia grega.

Poder-se-á entender o caráter único desse segundo componente o método da discuss o cr tica - se considerarmos a funç o antigamente estabelecida das escolas, especialmente das escolas religiosas e semi-religiosas. Sua funç o é, e tem sido sempre, a preservaç o da pureza do ensinamento do fundador da escola. De acordo com isso, mudanças na doutrina s o raras e com freq ncia devidas a erros ou mal-entendidos. Quando s o feitas conscientemente s o via de regra feitas sub-repticiamente, pois, de outra forma, as mudanças levam a cis es, a cismas.

Mas aqui, na escola $j$ nica, encontramos uma tradiç o de escola que preservou cuidadosamente o ensinamento de cada um de seus mestres, embora se desviando dele mais uma vez em cada nova geraç o.

Minha explicaç o conjetural desse fen meno único é que Tales, o fundador, encorajou Anaximandro, seu parente, disc pulo e mais tarde seu sucessor, a ver se poderia produzir uma explicaç o melhor do apoio da terra do que a que ele próprio tinha sido capaz de oferecer.

Como quer que tenha sido, a invenç o do método cr tico dificilmente poderia ter acontecido sem o impacto do choque cultural. Ele teve as mais tremendas conseq ncias. Em quatro ou cinco geraç es os gregos descobriram que a terra, a lua e o sol eram esferas; que a lua se movia em torno da terra, embora sempre "ansiosamente" contemplando o sol; e que isso poderia ser explicado pela suposiç o de que ela emprestava sua luz do sol. ${ }^{10} \mathrm{Um}$ pouco mais tarde eles conjeturaram que a terra girava e que a terra se movia em torno do sol. Mas essas últimas hipóteses, devidas escola plat nica e especialmente a Aristarco, foram logo esquecidas.

Essas descobertas cosmológicas e astron micas tornaram-se a base de toda a ci ncia futura. A ci ncia humana começou de uma audaz e auspicioso tentativa de entender criticamente o mundo em que vivemos. Este antigo sonho encontrou realizaç o em Newton. Podemos dizer que somente a partir de Newton a humanidade tornou-se plenamente consciente - consciente de sua posiç o no universo.

Pode-se mostrar que tudo isso é o resultado da aplicaç o do método da discuss o cr tica criaç o de mitos - s nossas tentativas de entender e explicar o nosso mundo. 


\section{VI}

Se recapitularmos este desenvolvimento, poderemos ent o entender melhor por que $\mathrm{n}$ o devemos esperar que qualquer discuss o $\mathrm{cr}$ tica de um assunto sério, qualquer "confrontaç o", produza resultados rápidos e finais. É dif cil obter a verdade. É preciso engenhosidade tanto na cr tica de velhas teorias como na invenç o imaginativa de novas teorias. Isso é assim n o apenas nas ci ncias, mas em todos os campos.

Discuss es cr ticas sérias s o sempre dif ceis. Sempre entram em jogo elementos humanos n o racionais. Muitos participantes de uma discuss o racional, isto é, uma discuss o cr tica, acham particularmente dif cil terem de desaprender o que a todo mundo é ensinado numa sociedade em que há debate, pois $\mathrm{t} \mathrm{m}$ que aprender que a vitória num debate $\mathrm{n}$ o é nada, ao passo que mesmo o menor esclarecimento do problema de alguém, mesmo a menor contribuiç o feita em direç o a um entendimento mais claro da própria posiç o de alguém ou da posiç o de um seu oponente, é um grande sucesso. Uma discuss o que voc vence, mas que n o o ajuda a mudar ou a pelo menos aclarar sua mente um pouco deveria ser considerada por voc como uma dura perda. Por esta mesma raz o nenhuma mudança na posiç o de alguém deve ser feita sub-repticiamente, mas ser sempre ressaltada e suas conseq ncias exploradas.

A discuss o racional nesse sentido é rara. Mas é um ideal importante e podemos aprender a desfrutá-lo. $\mathrm{N}$ o visa convers o e é modesta em suas expectativas: é suficiente, mais do que suficiente, se sentimos que podemos ver as coisas sob uma nova luz ou que chegamos, mesmo que só um pouco, mais perto da verdade.

\section{VII}

Mas voltarei agora ao mito do referencial. Há muitas tend ncias que podem contribuir para o fato de que esse mito é freq entemente tomado como uma verdade quase auto-evidente.

Eu já havia mencionado uma dessas tend ncias. Ela resulta de uma expectativa excessivamente otimista no que concerne ao resultado 
de uma discuss o; a expectativa de que toda discuss o frut fera levaria a uma decisiva e merecida vitória intelectual da verdade, representada por uma parte, sobre a falsidade, representada pela outra parte. Quando se descobre que $\mathrm{n}$ o é a isso a que uma discuss o normalmente chega, a decepç o torna uma expectativa excessivamente otimista num pessimismo geral no que concerne ao valor das discuss es.

Uma segunda tend ncia que merece escrut nio cuidadoso está associada ao relativismo cultural ou histórico, um ponto de vista cujos primórdios podem talvez ser discernidos em Heródoto, o pai da história.

Heródoto parece ter sido uma dessas pessoas um tanto incomuns cuja mente se ampliou graças a suas viagens. No começo, sem dúvida, sentiu-se chocado pelos costumes e instituiç es muito estranhos que encontrou no Oriente. Mas aprendeu a respeitá-los e a considerar alguns deles criticamente e a outros como resultados de acidentes históricos: aprendeu a ser tolerante e até adquiriu a habilidade de ver os costumes e as instituiç es de seu próprio pa s através dos olhos de seus anfitri es bárbaros.

Este é um estado de coisas saudável. Mas pode levar ao relativismo, isto é, ao ponto de vista de que n o há verdade absoluta ou objetiva, mas antes uma verdade para os gregos e outra para os eg pcios, e ainda outra para os s rios, e assim por diante.

$\mathrm{N}$ o penso que Heródoto tenha ca do nessa armadilha. Mas muitos o fizeram desde ent $\mathrm{o}-$ talvez inspirados por um admirável sentimento de toler ncia, que combinaram com uma lógica bastante dúbia.

Há uma vers o da idéia de relativismo cultural que é obviamente correta. Na Inglaterra, na Austrália e na Nova Zel ndia dirigimos do lado esquerdo da estrada, enquanto nos Estados Unidos e em muitos outros pa ses dirigimos do lado direito. O que se precisa é de alguma dessas regras de tr nsito, mas qual das duas - direita ou esquerda - é obviamente arbitrário e convencional. Existem muitas regras semelhantes de maior ou menor import ncia que s o puramente convencionais e costumeiras. Entre essas est o as diferentes regras de pronúncia e ortografia da 1 ngua inglesa nos Estados Unidos e na Inglaterra. Mesmo dois vocabulários completamente diferentes podem ser relacionados de maneira convencional estritamente parecida com as duas diferentes regras de tr nsito, desde que as estruturas gramaticais das duas 1 nguas sejam muito 
semelhantes. Podemos considerar tais vocabulários, ou tais regras, como sendo diferentes de maneira puramente convencional: $\mathrm{n}$ o há nada realmente a se escolher entre eles - nada que tenha import ncia.

Enquanto considerarmos somente costumes e regras convencionais tais como esses, $\mathrm{n}$ o haverá nenhuma chance de o mito do referencial ser tomado seriamente, pois uma discuss o entre um americano e um ingl $\mathrm{s}$ a respeito da regra de tr nsito provavelmente levará a um acordo. Ambos provavelmente ir o deplorar o fato de que suas regras n o coincidem. Ambos ir o concordar que em princ pio nada há a escolher entre as duas regras e que n o seria razoável esperar que os Estados Unidos adotassem a regra da $\mathrm{m}$ o esquerda só para estar de acordo com a $\mathrm{Gr}$-Bretanha; e ambos provavelmente concordar o que a $\mathrm{Gr}$-Bretanha $\mathrm{n}$ o pode no momento fazer uma mudança que pode ser desejável mas que seria extremamente custosa. Depois de assim ter chegado a acordo em todos os pontos, os dois participantes provavelmente ir o se separar com a sensaç $\mathrm{O}$ de que $\mathrm{n}$ o aprenderam nada com a discuss $\mathrm{o}$.

A situaç o muda quando consideramos outras instituiç es, leis ou costumes - aqueles, por exemplo, que se associam administraç o da justiça. Costumes e leis diferentes neste campo pode fazer muita diferença para aqueles que vivem sob eles. Alguns costumes podem ser muito cruéis, enquanto outros proporcionam ajuda mútua e al vio ao sofrimento. Alguns pa ses e suas leis respeitam a liberdade, enquanto outros o fazem menos ou n o o fazem absolutamente.

É minha opini o que uma discuss o cr tica dessas quest es importantes é n o somente poss vel, mas o mais urgentemente necessária. Isso é freq entemente tornado dif cil pela propaganda e por uma omiss o de informaç o fatual. Mas essas dificuldades n o s o insuperáveis. Assim, é poss vel combater a propaganda com informaç o e a informaç o, se dispon vel, nem sempre é desconsiderada, embora deva-se reconhecer que com freq ncia é desconsiderada.

Apesar de tudo isso, há algumas pessoas que defendem o mito de que referenciais de leis e costumes $\mathrm{n}$ o podem ser discutidos racionalmente. Asseveram que a moralidade é id ntica legalidade ou uso ou costume e que portanto é imposs vel julgar ou discutir se um sistema de costumes é moralmente melhor que outro, uma vez que o sistema de leis e costumes existente é o único padr o de moralidade poss vel. 
Este ponto de vista foi enunciado por Hegel com o aux lio das fórmulas: "O que é real é racional" e "O que é racional é real". Aqui "o que é" ou "o que é real" quer dizer o mundo, incluindo seus costumes e leis feitos pelo homem. Que estes sejam feitos pelo homem é negado por Hegel, que assevera que o Esp rito do Mundo ou a Raz o os fizeram e que aqueles que parecem $\mathrm{t}$-los feito - os grandes homens, os criadores da história - s o meramente os executores da raz o, sendo suas paix es o mais sens vel instrumento da raz o; eles s o os reveladores do Esp rito de seu Tempo, e, no final das contas, do Esp rito Absoluto, isto é, do Próprio Deus.

Este é precisamente um daqueles muitos casos em que os filósofos usam Deus para seus próprios fins privados; isto é, como uma escora para alguns de seus argumentos sem solidez.

Hegel era tanto um relativista quanto um absolutista: como sempre, ele tomava pelo menos dois caminhos e se dois caminhos $\mathrm{n}$ o fossem suficientes, ele tomava tr s. E foi o primeiro de uma longa corrente de filósofos pós-kantianos, isto é, filósofos pós-cr ticos ou pós-racionalistas principalmente filósofos alem es - que mantiveram o mito do referencial.

De acordo com Hegel, a própria verdade era tanto relativa como absoluta. Era relativa a cada referencial histórico e cultural: n o poderia haver, assim, nenhuma discuss o racional entre os referenciais, visto que cada um deles tinha um padr o de verdade diferente. Mas sua doutrina de que toda verdade era relativa aos diversos referenciais era absolutamente verdadeira, visto que era parte da própria filosofia relativista de Hegel.

\section{VIII}

A alegaç o de Hegel de que descobriu a verdade absoluta n o parece hoje atrair muitas pessoas. Mas sua doutrina da verdade relativa e seu mito do referencial ainda as atrai. O que os torna $t$ o atraentes é que confundem o relativismo com o insight verdadeiro de que todos os homens s o fal veis. Essa doutrina da falibilidade desempenhou um importante papel na história da filosofia desde seus primeiros dias - de Xenófanes e Sócrates até Charles Sanders Peirce - e penso que isso é da máxima import ncia. Mas $n$ o penso que possa ser usada para sustentar o relativismo com respeito verdade. 
Naturalmente, a doutrina da falibilidade humana pode ser validamente usada para argumentar contra essa espécie de absolutismo filosófico que alega possuir a verdade absoluta ou pelo menos um critério de verdade absoluta, tal como o critério cartesiano da clareza e distinç o ou algum outro critério intuitivo. Mas existe uma doutrina muito diferente da verdade absoluta, uma doutrina de fato falibilista, que assevera que os erros que cometemos podem ser erros absolutos, no sentido de que nossas teorias podem ser absolutamente falsas, que elas podem estar aquém da verdade. Assim, a noç o de verdade e de estar aquém da verdade podem representar padr es absolutos para o falibilista. Essas noç es s o uma grande ajuda nas discuss es cr ticas.

Essa teoria da verdade absoluta ou objetiva foi revivida por Alfred Tarski, que também provou que n o pode haver nenhum critério universal de verdade. $\mathrm{N}$ o há qualquer conflito entre a teoria de Tarski da verdade absoluta ou objetiva e a doutrina da falibilidade. ${ }^{11}$

Mas a noç o de verdade de Tarski n o é uma noç o relativa? $\mathrm{N}$ o é ela relativa linguagem qual pertence o enunciado cuja verdade está sendo discutida?

A resposta a esta quest o é "n o". A teoria de Tarski diz que um enunciado de alguma linguagem, digamos, o portugu s, é verdadeiro se e somente se corresponde aos fatos; e a teoria de Tarski implica que sempre que haja outra linguagem, digamos, o franc s, em que podemos descrever o mesmo fato, ent o o enunciado em franc s que descreve esse fato será verdadeiro se e somente se o enunciado correspondente em portugu s é verdadeiro. Assim, é imposs vel, de acordo com a teoria de Tarski, que dois enunciados que s o traduç es um do outro, um possa ser verdadeiro e o outro falso. Portanto, de acordo com a teoria de Tarski, a verdade $n o$ depende da linguagem nem é relativa linguagem. Faz-se refer ncia linguagem somente devido improvável mas trivial possibilidade de que os mesmos sons e s mbolos possam ocorrer em duas linguagens diferentes e possam ent o talvez descrever dois fatos totalmente diferentes.

Contudo, pode facilmente acontecer que um enunciado de uma linguagem seja intraduz vel em outra, ou, em outras palavras, que um fato, ou um estado de coisas, que possa ser descrito em uma linguagem, n o possa ser descrito em outra.

Alguém que possa falar mais de uma 1 ngua sabe, naturalmente, que traduç es perfeitas de uma 1 ngua para outra s o muito raras, se é que 
existem. Mas essa dificuldade bem conhecida de todos os tradutores deve ser claramente distinguida da situaç o aqui discutida - ou seja, a impossibilidade de descrever em uma linguagem um estado das coisas que pode ser descrito em alguma outra linguagem. A dificuldade comum e bem conhecida consiste em algo completamente diferente, ou seja: um enunciado conciso, simples e facilmente compreens vel em franc s ou portugu s pode precisar de uma vers o altamente complexa e embaraçosa para, digamos, o alem o, e uma vers o que é até dif cil de entender em alem o. Em outras palavras, a dificuldade comum, conhecida por todo tradutor, é que uma traduç o esteticamente adequada pode ser imposs vel, n o que qualquer traduç o do enunciado em quest o seja imposs vel. (Estou falando aqui de um enunciado fatual, $\mathrm{n}$ o de um poema ou de um aforismo ou um bon mot ou de um enunciado sutilmente ir nico ou que expressa um sentimento do locutor.)

Todavia, n o pode haver dúvida de que pode surgir uma impossibilidade mais radical; por exemplo, podemos construir linguagens artificiais que cont $\mathrm{m}$ somente predicados de um só termo, de modo que podemos dizer nessas linguagens "Paulo é alto" e "Pedro é baixo", mas n o "Paulo é mais alto do que Pedro".

Mais interessantes do que tais linguagens artificiais s o algumas 1 nguas vivas. Aqui podemos aprender muito com Benjamin Lee Whorf. ${ }^{12}$ Whorf foi talvez o primeiro a chamar a atenç o para a import ncia de certos tempos de verbo da l ngua hopi. Estes tempos verbais s o sentidos na experi ncia de um locutor hopi como descrevendo alguma parte do estado das coisas que ele tenta descrever em seu enunciado. Eles n o podem ser adequadamente vertidos em portugu s, porque só podemos explicá-los por um circunlóquio, fazendo refer ncia a certas expectativas do locutor em vez de a aspectos dos estados de coisas objetivos.

Whorf dá o seguinte exemplo. Há dois tempos verbais em 1 ngua hopi que poderiam ser vertidos inadequadamente para o portugu s pelos dois enunciados seguintes:

"Fred começou a estar cortando lenha"; e

"Fred começou a cortar lenha".

O primeiro seria usado pelo locutor hopi se ele espera que Fred vai continuar cortando lenha por algum tempo. Se o locutor $n$ o espera que 
Fred vá continuar a sua aç o de cortar lenha, ent o ele $n$ o dir , em l ngua hopi, "Fred começou a estar cortando lenha"; ele usará aquele outro tempo verbal vertido por "Fred começou a cortar lenha". Mas a quest o real é que o locutor hopi n o deseja, pelo uso de seus tempos verbais, meramente expressar suas diferentes expectativas. Ele antes deseja dois diferentes estados de coisas - duas diferentes situaç es objetivas, dois diferentes estados do mundo objetivo. Pode-se dizer que o primeiro tempo verbal descreve o começo de um estado continuado ou de um processo algo repetitivo, enquanto o outro descreve o começo de um evento de curta duraç o. Assim, o locutor hopi pode tentar traduzir o hopi para o portugu s dizendo: "Fred começou a estar dormindo", em contraposiç o a "Fred começou a dormir", porque dormir é antes um processo que um evento.

Tudo isso está muito simplificado: uma reformulaç o completa da descriç o de Whorf da complexa situaç o ling stica poderia facilmente ocupar um artigo inteiro. A principal conseq ncia para o meu tema que parece emergir das situaç es descritas por Whorf e mais recentemente discutidas por Quine, é esta: embora n o possa haver qualquer relatividade ling stica a respeito da verdade de qualquer enunciado, existe a possibilidade de que um enunciado possa ser intraduz vel em outra linguagem. Pois as duas linguagens podem ter constru do no mbito respectivo de suas próprias gramáticas dois pontos de vista diferentes do material de que o mundo é feito ou das caracter sticas estruturais básicas do mundo. Na terminologia de Quine, isto pode ser chamado de "relatividade ontológica" da linguagem. ${ }^{13}$

Afirmo que a possibilidade de que alguns enunciados sejam intraduz veis é uma das mais radicais conseq ncias que podemos extrair do que Quine chama de "relatividade ontológica". No entanto, de fato a maior parte das linguagens humanas parecem ser efetivamente intertraduz veis. Podemos dizer que elas s o na maior parte imperfeitamente intertraduz veis, principalmente devido relatividade ontológica, embora naturalmente também por outras raz es. Por exemplo, apelos ao nosso senso de humor, ou comparaç es com um evento histórico ou local bem conhecido que se tornou t pico podem ser completamente intraduz veis. 


\section{IX}

É óbvio que essa situaç o deve tornar a discuss o racional bastante dif cil se os participantes formaram-se em diferentes partes do mundo e falam 1 nguas diferentes. Descobri porém que estas dificuldades com freq ncia podem ser sobrepujadas. Tenho tido estudantes na London School of Economics vindos de diversas partes da África, do Oriente Médio, da Índia, do Sudeste Asiático, da China e do Jap o, e descobri que as dificuldades geralmente podiam ser vencidas com um pouco de paci ncia de ambos os lados. Sempre que havia um obstáculo importante a superar, era via de regra o resultado de instruç o com idéias ocidentais. O ensino acr tico e dogmático em escolas e universidades mal ocidentalizadas, e particularmente a instruç o com verbosidade ocidental e com ideologias ocidentais foram, na minha experi ncia, obstáculos muito mais graves para a discuss o racional do que qualquer hiato cultural ling stico.

Minha experi ncia me sugeriu que o choque cultural pode perder um pouco de seu valor se uma das culturas em choque se considera como universalmente superior e ainda mais se é assim considerada pela outra: isto destrói o principal valor do choque cultural, pois o maior valor do choque cultural reside no fato de que pode evocar uma atitude cr tica. E mais especialmente, se uma das partes vem a ser convencida de sua inferioridade, ent o a atitude cr tica de aprendizado a partir da outra será substitu da por uma espécie de aceitaç o cega, um pulo cego em um novo c rculo mágico, ou uma convers o, como é t o freq entemente descrita pelos fide stas e existencialistas.

Acredito que a relatividade ontológica, embora seja um obstáculo para a fácil comunicaç o, pode-se provar de imenso valor em todos os casos mais importantes de choque cultural se ele puder ser superado lentamente. Pois significa que os parceiros no conflito podem libertarse de preconceitos dos quais est o inconscientes - de admitir inconscientemente teorias que, por exemplo, podem estar imersas na estrutura lógica de suas linguagens. Uma tal libertaç o pode ser o resultado da or tica estimulada pelo choque cultural.

O que acontece em tais casos? Comparamos e contrastamos a nova linguagem com a nossa ou com outras que conhecemos bem. No estudo 
comparativo dessas linguagens usamos, via de regra, nossa própria 1 ngua como uma metalinguagem - isto é, como uma linguagem na qual falamos de outras linguagens que s o os objetos investigados, incluindo nossa própria linguagem, e as comparamos. As linguagens investigadas $\mathrm{s} \mathrm{o}$ as linguagens-objeto. Levando a cabo a investigaç o, somos forçados a considerar a nossa própria linguagem - digamos, o portugu s-de maneira cr tica, como um conjunto de regras e usos que podem ser algo estreitos, visto que s o completamente incapazes de apreender ou descrever as espécies de entidades que as outras 1 nguas sup em existir. Mas essa descriç o das limitaç es do portugu s como linguagem-objeto é levada a cabo no portugu s como metalinguagem. Assim, somos forçados, por este estudo comparativo, a transcender precisamente aquelas limitaç es que estamos estudando. E o ponto interessante é que somos bem-sucedidos nisso. O meio de transcender a nossa linguagem é a $\mathrm{cr}$ tica.

O próprio Whorf e alguns de seus seguidores sugeriram que vivemos numa espécie de pris o intelectual, uma pris o formada pelas regras estruturais de nossa linguagem. Estou pronto a aceitar essa metáfora, embora deva acrescentar a ela que é uma pris o singular, na medida em que normalmente somos inconscientes disso. Nos tornamos conscientes dela através do choque cultural. Mas depois, essa própria consci ncia nos permite romper a pris o se o desejarmos: podemos transcender nossa pris o estudando a nova linguagem e comparando-a com a nossa própria.

O resultado será uma nova pris o. Mas será uma pris o muito maior e mais ampla; e, mais uma vez, n o iremos suportá-la; ou antes, sempre que venhamos a faz -lo, somos livres para examiná-la criticamente, e assim de romp -la novamente, numa outra pris o ainda mais ampla.

As pris es s o os referenciais. E aqueles que n o gostam de pri$s$ es ir o se opor ao mito do referencial. Eles receber o bem uma discuss o com um parceiro que venha de outro mundo, de outro referencial, pois isso lhes dá uma oportunidade de descobrir suas cadeias até agora $\mathrm{n} o$ percebidas, de romp -las e assim transcend -las. Esse rompimento da pris o em que se encontra $\mathrm{n}$ o é, naturalmente, um assunto de rotina: ${ }^{14}$ só pode ser resultado de um esforço cr tico - de um esforço criativo. 


\section{X}

No restante deste artigo tentarei aplicar esta breve análise a alguns problemas que foram levantados em um campo no qual estou muito interessado - a filosofia da ci ncia.

Faz agora cinq enta anos que cheguei a um ponto de vista muito semelhante ao do mito do referencial; e n o só cheguei a ele, mas imediatamente o superei. Foi durante as grandes e acaloradas discuss es após a Primeira Guerra Mundial que descobri o quanto era dif cil chegar a algum lugar com pessoas que viviam em um referencial fechado; quero aludir a pessoas como os marxistas, os freudianos e os adlerianos. Nenhum deles poderia jamais ser abalado em seu ponto de vista adotado. Cada argumento contra seu referencial era por eles interpretado de tal modo a se ajustar a ele; e se isso se mostrasse dif cil, ent o era sempre poss vel fazer uma análise psicanal tica ou sociológica do oponente: a cr tica de idéias marxistas devia-se ao preconceito de classe, a cr tica de idéias freudianas devia-se repress o e a cr tica de idéias adlerianas devia-se ao desejo de provar sua superioridade, um desejo que se devia a uma tentativa de compensar um sentimento de inferioridade.

Achei o padr o estereotipado dessas atitudes deprimente e repulsivo, tanto mais quanto eu n o podia descobrir nada dessa espécie nos debates dos $\mathrm{f}$ sicos a respeito da teoria geral de Einstein, embora também fosse calorosamente debatida na época.

A liç o que tirei dessas experi ncias foi esta: as teorias s o importantes e indispensáveis porque sem elas $\mathrm{n}$ o poder amos nos orientar no mundo - $\mathrm{n}$ o poder amos viver. Até mesmo nossas observaç es s o interpretadas com sua ajuda. $\mathrm{O}$ marxista literalmente $\mathrm{v}$ a luta de classes em toda parte; ele cr assim que somente aqueles que deliberadamente fecham seus olhos podem deixar de ver isso. $\mathrm{O}$ freudiano $\mathrm{v}$ em toda parte repress o e sublimaç o; o adleriano $\mathrm{v}$ como os sentimentos de inferioridade se expressam em toda aç o e em todo proferimento, quer seja um proferimento de inferioridade ou de superioridade.

Isso mostra que nossa necessidade de teorias é imensa, e assim é o poder das teorias. Assim, é da maior import ncia resguardar-se de ficar viciado em qualquer teoria em particular: devemos $\mathrm{n}$ o nos deixar ser apanhados numa pris o mental. Eu n o conhecia a teoria do choque cul- 
tural na época, mas certamente fiz uso de meus choques com os viciados nos diversos referenciais para gravar em minha mente o ideal de libertaç o da pris o intelectual de uma teoria qual uma pessoa poderia inconscientemente ficar presa, em qualquer momento de sua vida.

É bastante óbvio que esse ideal de autolibertaç o, de rompimento da pris o em que se encontra no momento, poderia por sua vez se tornar parte de um referencial ou de uma pris $\mathrm{o}-\mathrm{ou}$, em outras palavras, que nunca podemos estar absolutamente livres. Mas podemos ampliar nossa pris o e pelo menos podemos deixar para trás a estreiteza de quem está viciado por seus grilh es.

Assim, nosso ponto de vista do mundo está em qualquer momento necessariamente impregnado de teoria. Mas isso n o nos impede de progredir para teorias melhores. Como faz -lo? O passo essencial é a formulaç o ling stica de nossas crenças. Isso as objetiva e torna poss vel que elas sejam alvos de cr tica. Assim, nossas crenças s o substitu das por teorias concorrentes, por conjeturas concorrentes. E através da discuss o cr tica dessas teorias podemos progredir.

Desse modo, devemos exigir de qualquer teoria melhor, ou seja, de qualquer teoria que possa ser considerada como progredindo para além de alguma teoria pior, que ela possa ser comparada com esta última. Em outras palavras, que as duas teorias $n$ o sejam "incomensuráveis", para usar um termo agora em moda, introduzido neste contexto por Thomas Kuhn.

(Note-se que duas teorias logicamente incompat veis ser o, em geral, "comensuráveis". Pretende-se que a incomensurabilidade seja muito mais radical do que a incompatibilidade: enquanto a incompatibilidade é uma relaç o lógica e assim apela para um referencial lógico, a incomensurabilidade sugere a n o exist ncia de um referencial lógico comum.)

Por exemplo, a astronomia de Ptolomeu está longe de ser incomensurável com aquela de Aristarco e Copérnico. Sem dúvida, o sistema copernicano nos permite ver o mundo de uma maneira totalmente diferente; sem dúvida há, psicologicamente, uma mudança de Gestalt, como Kuhn a chama. Isso é psicologicamente muito importante. Mas podemos comparar os dois sistemas logicamente. De fato, foi um dos principais argumentos de Copérnico que todas as observaç es astron micas que podem se ajustar a um sistema geoc ntrico podem, por um simples método de translaç o, ser sempre ajustadas a um sistema helioc ntrico. Existe 
sem dúvida uma diferença extremamente importante entre esses dois pontos de vista do universo e a magnitude do abismo entre esses dois pontos de vista pode bem nos fazer estremecer. Mas n o há nenhuma dificuldade em compará-los. Por exemplo, podemos assinalar as colossais velocidades que a esfera giratória das estrelas fixas devem dar s estrelas que est o próximas do seu equador, enquanto a rotaç o da Terra, que no sistema de Copérnico substitui a das estrelas fixas, envolve velocidades muito menores. Isso, juntamente com alguma familiaridade prática com as forças centr fugas, bem pode ter servido como um importante ponto de comparaç o para aqueles que tinham de escolher entre os dois sistemas.

Afirmo que essa espécie de comparaç o entre sistemas é sempre poss vel. Afirmo que teorias que oferecem soluç es aos mesmos problemas ou a problemas estreitamente relacionados s o via de regra comparáveis e discuss es entre elas s o sempre poss veis e frut feras; e elas n o apenas s o poss veis, mas elas efetivamente ocorrem.

\section{XI}

Algumas pessoas $\mathrm{n}$ o pensam que estas asserç es $\mathrm{s}$ o corretas e isso resulta num ponto de vista da ci ncia e de sua história muito diferente do meu. Esboçarei brevemente tal ponto de vista da ci ncia.

Os proponentes ${ }^{15}$ de tal ponto de vista podem observar que os cientistas est o normalmente engajados em estreita cooperaç o e discuss o; e os proponentes argumentam que essa situaç o se fez poss vel pelo fato de que os cientistas normalmente operam no interior de um referencial comum com o qual se comprometeram. (Referenciais dessa espécie parecem estar estreitamente relacionados ao que Karl Mannheim costumava chamar de "ideologias totais". $\left.{ }^{16}\right)$ Os per odos durante os quais os cientistas permanecem comprometidos a um referencial s o considerados como t picos: s o per odos de "ci ncia normal" e os cientistas que trabalham dessa maneira s o considerados como "cientistas normais".

A ci ncia nesse sentido é ent o contrastada com a ci ncia num per odo de crise ou revoluç o. Esses s o per odos em que o referencial 
teórico começa a rachar e no fim se rompe. É ent o substitu do por um novo. A transiç o de um velho referencial para um novo é considerada como um processo que deve ser estudado n o de um ponto de vista lógico (pois ele é essencialmente, n o totalmente, ou mesmo principalmente, racional), mas de um ponto de vista psicológico e sociológico. Há talvez alguma coisa como "progresso" na transiç o para um novo referencial teórico. Mas este n o é um progresso que consiste em se chegar mais perto da verdade e a transiç o n o é guiada por uma discuss o racional dos méritos relativos das teorias concorrentes. Ela $n$ opode ser assim guiada dado que se pensa que uma discuss o genuinamente racional imposs vel sem um referencial estabelecido. Sem um referencial nem mesmo se pensa que é poss vel concordar com o que constitui um ponto de "mérito" numa teoria. (Alguns protagonistas desse ponto de vista pensam mesmo que podemos falar de verdade apenas com relaç o a um referencial.) A discuss o racional é assim imposs vel se é o referencial que está sendo desafiado. E é por isso que os dois referenciais - o velho e o novo $-\mathrm{t} \mathrm{m}$ sido descritos algumas vezes como incomensur veis.

Uma raz o adicional pela qual se diz algumas vezes que os referenciais s o incomensuráveis parece ser a seguinte: pode-se pensar que um referencial consiste n o apenas numa "teoria dominante", mas também que é, em parte, uma entidade psicológica e sociológica. Consiste numa teoria dominante junto com o que se poderia chamar de uma maneira de ver as coisas em sintonia com a teoria dominante, incluindo algumas vezes até um modo de ver o mundo e um modo de vida. De acordo com isso, um tal referencial constitui um v nculo social entre seus devotos: ele os une em grande parte como o faz uma igreja, ou um credo pol tico ou art stico, ou uma ideologia.

Esta é uma explicaç o adicional da afirmada incomensurabilidade: é compreens vel que dois modos de vida e dois modos de ver o mundo sejam incomensuráveis. Todavia, quero salientar que duas teorias que tentam resolver a mesma fam lia de problemas, inclusive de sua prole (suas crianças problemáticas), $n$ o precisam ser incomensuráveis, e que em ci ncia, ao contrário da religi o, as teorias é que s o soberanas. $\mathrm{N}$ o desejo negar que haja uma coisa tal como uma "abordagem cient fica", ou um "modo de vida" cient fico: ou seja, o modo de vida daqueles homens devotados ci ncia. Pelo contrário, afirmo que o modo de vida cient fico envolve um 
ardente interesse em teorias cient ficas objetivas - nas teorias em si mesmas e no problema de sua verdade, ou de sua proximidade em relaç o verdade. E este interesse é um interesse or tico, um interesse argumentativo. Assim, isso n o produz, como algumas outras crenças, nada que se pareça com a descrita "incomensurabilidade".

Parece-me que existem muitos contra-exemplos para a teoria da história da ci ncia que tenho discutido. Primeiro, há contra-exemplos que mostram que a exist ncia de um "referencial”, e do trabalho que se dá em seu interior, n o caracteriza a ci ncia. A filosofia durante o per odo escolástico, a astrologia e a teologia s o contra-exemplos tais. Segundo, há contra-exemplos que mostram que pode haver várias teorias dominantes lutando pela supremacia numa ci ncia, e pode mesmo haver discuss es frut feras entre elas. Meu principal contra-exemplo sobre este tópico é a teoria da constituiç o da matéria, na qual as teorias do atomismo e da continuidade estiveram, frutiferamente, em guerra desde os pitagóricos e Parm nides, Demócrito e Plat o até Heisenberg e Schr dinger. N o penso que essa guerra possa ser descrita como caindo na pré-história da ci ncia ou na história da pré-ci ncia. Outro contra-exemplo dessa segunda espécie é constitu do pelas teorias do calor. Mesmo depois de Black tivemos as teorias ${ }^{17}$ do calor como fluido em guerra com as teorias cinética e fenomenológica; e o conflito entre Ernst Mach e Max Planck ${ }^{18}$ n o foi nem caracter stico de uma crise nem ocorreu no interior de um referencial, nem de fato podia ser descrito como pré-cient fico. Outro exemplo é o conflito entre Cantor e seus cr ticos (especialmente Kronecker), que mais tarde continuou na forma de interc mbio entre Russell e Poincaré, Hilbert e Brouwer. Por volta de 1925 houve pelo menos tr s referenciais nitidamente opostos envolvidos, divididos por diverg ncias por demais amplas para serem conciliadas. Mas as discuss es continuaram e lentamente mudaram de caráter. Nesse meio tempo n o somente ocorreram discuss es frut feras, mas também tantas $\mathrm{s}$ nteses que os rancores do passado est o quase esquecidos. Em terceiro lugar, há contra-exemplos que mostram que discuss es racionais frut feras podem continuar entre devotos de uma teoria dominante recem estabelecida e céticos inconvictos. Este é o caso dos Dois $M$ ximos Sistemas de Galileu; o de alguns dos escritos "populares” de Einstein, ou da importante cr tica de E. Kretschmann (1917) ao princ pio da covari ncia de Einstein, ou da cr tica da teoria geral de Einstein recentemente apresentada por Dicke; e também as famosas discuss es de 
Einstein com Bohr. Seria muito incorreto dizer que essas últimas n o foram frut feras, pois $\mathrm{n}$ o apenas Bohr alegou que melhoraram muito seu entendimento da mec nica qu ntica, mas também levaram ao famoso artigo de Einstein, Podolsky e Rosen que produziu toda uma literatura de considerável import ncia, e pode ainda levar a mais: ${ }^{19}$ a nenhum artigo que é discutido por especialistas reconhecidos durante trinta e cinco anos pode ser negado seu status e import ncia cient fica, mas este artigo estava, certamente, criticando (de fora) todo o referencial que tinha sido estabelecido pela revoluç o de 1925-1926. A oposiç o a esse referencial o referencial de Copenhague - é continuada por uma minoria qual pertencem, por exemplo, de Broglie, Bohm, Landé e Vigier - além daqueles nomes mencionados na nota anterior. ${ }^{20}$

Assim, as discuss es podem prosseguir todo o tempo; e embora haja sempre tentativas de transformar a sociedade dos cientistas numa sociedade fechada, essas tentativas n o foram bem-sucedidas. Em minha opini o, elas seriam fatais para a ci ncia.

Os proponentes do ponto de vista do mito do referencial distinguem nitidamente entre per odos racionais de ci ncia conduzida no interior de um referencial (que podem ser descritos como per odos de ci ncia fechada ou autoritária) e per odos de crise e revoluç o, que podem ser descritos como o salto quase irracional (comparável a uma convers o religiosa) de um referencial para outro.

Há sem dúvida tais saltos irracionais, tais convers es, como foram descritas. Sem dúvida há mesmo cientistas que seguem exatamente a liderança de outros, ou cedem press o social, e aceitam uma nova teoria como uma nova fé por que os especialistas, as autoridades, a aceitaram. Admito, com pesar, que há modas em ci ncia e que também existe press o social.

Admito mesmo que pode chegar o dia em que a comunidade social dos cientistas consistirá principalmente ou exclusivamente de cientistas que aceitam acriticamente um dogma dominante. Eles ser o normalmente influenciados por modas; aceitar o uma teoria pelo fato de que é a última palavra e porque temem ser considerados como retardatários.

Afirmo, todavia, que isso será o fim da ci ncia como a conhecemos - o fim da tradiç o criada por Tales e Anaximandro e redescoberta por Galileu. Enquanto a ci ncia for a busca da verdade, ela será a discus$s$ o racional, cr tica entre teorias concorrentes e a discuss o cr tica racional 
da teoria revolucionária. Essa discuss o decide se a nova teoria deve ou n o ser considerada como melhor que a velha teoria: isto é, se deve ou n o ser considerada como um passo em direç o verdade.

\section{XII}

Quase quarenta anos atrás salientei que mesmo observaç es e relatórios de observaç es est o sob a influ ncia de teorias ou, se se quiser, sob a influ ncia de um referencial. Realmente, n o há uma coisa tal como uma observaç o n o interpretada, uma observaç o que n o seja impregnada de teoria. De fato, nossos próprios olhos e ouvidos s o o resultado de adaptaç es evolutivas - ou seja, do método de tentativa e erro que corresponde ao método de conjeturas e refutaç es. Esses dois métodos s o ajustamentos $\mathrm{s}$ regularidades ambientais. Um simples exemplo mostrará que as experi ncias visuais comuns $\mathrm{t} \mathrm{m}$ um sentido absoluto pré-parmenidiano de cima e baixo constitu do em seu interior - um sentido que sem dúvida tem base genética. $\mathrm{O}$ exemplo é o seguinte: um quadrado que repousa sobre um de seus lados mostra-se a todos nós como uma figura diferente de um quadrado que repousa sobre uma de suas arestas. Há uma real mudança de Gestalt na passagem de uma figura para a outra.

Mas afirmo que o fato de que as observaç es s o impregnadas de teoria n o leva a incomensurabilidade entre observaç es ou teorias. Pois as velhas observaç es podem ser conscientemente reinterpretadas: podemos aprender que os dois quadrados s o diferentes posiç es do mesmo quadrado. Isso se torna até mais fácil precisamente devido s interpretaç es baseadas geneticamente: sem dúvida nos entendemos uns com os outros $\mathrm{t}$ o bem em parte porque partilhamos muitos mecanismos fisiológicos que est o constitu dos em nosso sistema genético.

Afirmo todavia que nos é poss vel transcender nossa fisiologia baseada geneticamente. Fazemos isso através do método cr tico. Podemos até entender um pouquinho da linguagem das abelhas. Esse entendimento é reconhecidamente conjetural e rudimentar. Mas quase todo entendimento é conjetural e no in cio a decifraç o de uma nova linguagem é sempre rudimentar. 
É o método da ci ncia, o método da discuss o cr tica, que torna poss vel para nós transcender $\mathrm{n}$ o apenas nossos referenciais culturalmente adquiridos mas mesmo nossos referenciais cong nitos. Esse método nos tem feito transcender $\mathrm{n}$ o somente nossos sentidos, mas também nossa tend ncia em parte inata de considerar o mundo como um universo de coisas identificáveis e suas propriedades. Desde Heráclito tem havido revolucionários que nos $\mathrm{t} \mathrm{m}$ dito que o mundo consiste de processos e que as coisas s o coisas apenas na apar ncia: na realidade elas s o processos. Isto mostra como o pensamento cr tico pode desafiar e transcender um referencial, mesmo se está enraizado n o apenas em nossa linguagem convencional, mas em nossa genética - no que pode ser chamado de a própria natureza humana. Todavia, nem mesmo essa revoluç o produz uma teoria incomensurável com sua predecessora: a própria tarefa da revoluç o foi a de explicar a velha categoria de "coisidade" [thing-hood] por uma teoria de maior profundidade.

\section{XIII}

Posso talvez mencionar também que há uma forma muito especial do mito do referencial que é particularmente difundida. É o ponto de vista de que, antes da discuss o, dever amos chegar a um acordo sobre nosso vocabulário - talvez pela "definiç o de nossos termos".

Critiquei esse ponto de vista em diversas ocasi es e n o tenho espaço para faz -lo mais uma vez. ${ }^{21}$ Apenas quero deixar claro que existem as mais fortes raz es poss veis contra esse ponto de vista; todas as definiç es, inclusive as chamadas "definiç es operacionais", podem apenas deslocar o problema do significado dos termos em quest o para os termos definidores; assim, a exig ncia de definiç es leva a uma regress o infinita, a menos que admitamos os chamados termos "primitivos", isto é, termos indefinidos. Mas esses s o, via de regra, n o menos problemáticos do que a maioria dos termos definidos. 


\section{XIV}

$\mathrm{Na}$ última seç o deste artigo discutirei brevemente o mito do referencial de um ponto de vista lógico: tentarei algo como um diagnóstico lógico da doença. ${ }^{22}$

O mito do referencial é claramente a mesma coisa que a doutrina de que $\mathrm{n}$ o se pode discutir racionalmente nada que seja fundamental; ou que uma discuss o racional de princ pios é imposs vel.

Esta doutrina é, logicamente, um resultado do ponto de vista equivocado de que toda discuss o racional deve começar de alguns princ pios ou, como s o freq entemente chamados, axiomas, que por sua vez devem ser aceitos dogmaticamente se desejamos evitar uma regress o infinita uma regress o devida ao fato alegado de que, quando se discute racionalmente a validade de nossos princ pios ou axiomas, devemos novamente apelar para princ pios ou axiomas.

Usualmente aqueles que $\mathrm{t} \mathrm{m}$ visto esta situaç o ou insistem dogmaticamente na verdade de um referencial de princ pios ou axiomas, ou se tornam relativistas: dizem que há diferentes referenciais e que n o há discuss o racional poss vel entre eles, e portanto nenhuma escolha racional.

Mas tudo isso é equivocado, pois por trás disso há a suposiç o tácita de que uma discuss o racional deve ter o caráter de uma justificaç o, ou de uma prova ou uma demonstraç o, ou de uma derivaç o lógica a partir de premissas admitidas. Mas a espécie de discuss o que se dá nas ci ncias naturais poderia ter ensinado aos nossos filósofos que há também outra espécie de discuss o racional: uma discuss o cr tica que n o procure provar ou justificar ou estabelecer uma teoria, que n o a derive de algumas premissas maiores, mas que tente testar a teoria em discuss o descobrindo se suas conseq ncias l gicas s o todas aceitáveis, ou se ela tem, talvez, algumas conseq ncias indesejáveis.

Podemos assim distinguir logicamente entre $u m m$ todo equivocado de criticar e um $m$ todo correto de criticar. $\mathrm{O} m$ todo equivocado parte da quest o: como podemos estabelecer ou justificar nossa tese ou nossa teoria? Conduz assim ao dogmatismo; ou a uma regress o infinita; ou doutrina relativista dos referenciais racionalmente incomensuráveis. Em contraste, o $m$ todo correto de discuss o cr tica parte da quest o: quais s o as conseq $n$ cias de nossa tese ou de nossa teoria? S o todas aceitáveis para nós? 
Consiste assim em comparar as conseq ncias de diferentes teorias (ou, se se quiser, de diferentes referenciais) e tentar descobrir quais das teorias ou referencias concorrentes $t \mathrm{~m}$ conseq ncias que nos pareçam prefer veis. É, assim, consciente da falibilidade de todos os nossos métodos e tenta substituir todas as nossas teorias por outras melhores. Reconhecidamente, é uma tarefa dif cil, mas de modo nenhum imposs vel.

Em resumo: os referenciais, como as linguagens, podem ser barreiras; mas um referencial estranho, assim como um 1 ngua estrangeira, $\mathrm{n}$ o é uma barreira absoluta. E assim como romper uma barreira ling stica é dif cil mas de muito valor para nós, e provavelmente compensará nossos esforços n o somente ampliando nosso horizonte intelectual mas também nos oferecendo muito prazer, o mesmo se dá com o rompimento da barreira de um referencial. Um rompimento dessa espécie é uma descoberta para nós e pode s -lo também para a ci ncia.

Penn, Buckinghamshire
Inglaterra

Outubro de 1972

\section{Notas}

* Publicado originalmente com o t tulo "The Myth of the Framework". In: Joseph C. Pitt \& Marcello Pera (Eds.) - Rational Changes in Science: Essays on Scientific Reasoning - Reidel, Dordrecht, 1976, p. 35-62. () Sir Karl Popper 1976.

Traduç o de Mário A. Eufrásio (Departamento de Sociologia FFLCH-USP, Pesquisador do CNPq) e de Pedro Motta de Barros (doutorando em história da ci ncia, pesquisador do Centro de História da $\mathrm{Ci}$ ncia da Universidade de S o Paulo-CHC/USP).

** O presente texto baseia-se em artigo que preparei pela primeira vez em 1965. Estou em débito com Arne Petersen e Jeremy Shearmur por diversas sugest es e correç es. A ep grafe foi extra da do parágrafo 49D do Cr ton, de Plat o. 
Fonte: Eugene Freeman (Ed.), The Abdication of Philosophy and Public Good - Essays in Honor of Paul Arthur Schilpp - Open Court, La Salle (III.), 1976, p. 24-48.

1 Heródoto, III, 38. Refiro-me a esta passagem na n. 3 do cap. 5 de meu Open Society and Its Enemies, George Routledge \& Sons, Londres, 1945; Princeton University Press, Princeton, 5. ed. rev., 1966, vol. I [Trad. brasileira: A Sociedade Aberta e Seus Inimigos, (2 vols.) Itatiaia/ Edusp, Belo Horizonte/S o Paulo, 1974].

2 A distinç o entre natureza e convenç o é discutida em meu Open Societty, vol. I, cap. 5, onde me refiro a P ndaro, Heródoto, Protágoras, Antifo, Arquelau e especialmente a Plat o, Leis (cf. n. 3, 7, 10, 11 e 28 do cap. 5 e o texto). Embora eu mencione (p. 60) a import ncia da "compreens o de que os tabus s o diferentes em tribos diversas", e embora eu mencione (justamente) Xenófanes (n. 7) e sua profiss o como um "bardo itinerante" (n. 9 do cap. 10), n o compreendi completamente, ent o, o papel desempenhado pelo choque cultural na evoluç o do pensamento cr tico, como testemunhado pela contribuiç o feita por Xenófanes, Heráclito e Parm nides (ver esp. n. 11 do cap. 5 de Open Society) ao problema de natureza ou realidade ou verdade versus convenç o ou opini o. Ver também meu Conjectures and Refutations: The Growth of Scientific Knowledge, Basic Books, N. York, 1963; Routledge \& Kegan Paul, 4. ${ }^{a}$ ed. rev., Londres, 1972; passim. [Trad. brasileira: Conjecturas e Refutaç es: o Progresso do Conhecimento Cient fico, Ed. da Universidade de Bras lia, Bras lia, s. d. (1981?)].

3 Cf. meu Conjectures and Refutations, 4. ${ }^{\mathrm{a}}$ ed. rev., p. 152 e segs. As primeiras duas linhas de meu texto s o os fragmentos B 16, e as quatro seguintes os fragmentos B 15 . Os restantes tr s fragmentos $\mathrm{s}$ o os $\mathrm{B}$ 18, 35 e 34 (conforme Diels-Kranz, Fragmente der Vorsokratiker, 5. ${ }^{a}$ ed.) As traduç es s o minhas. Note-se, nas duas últimas linhas citadas, o contraste entre a única verdade final e as muitas presunç es, ou opini es, ou conjeturas.

4 Parm nides usou a terminologia de Xenófanes; ver Conjectures and

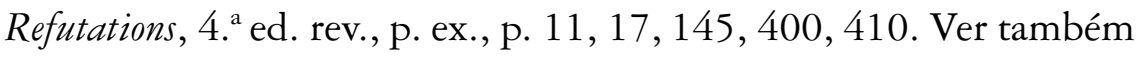
meu Open Society, vol. I, n. 56, seç o 8 do cap. 10, p. 312.

5 Ver o comentário de Parm nides, no fragmento B 6, sobre a confusa horda de mortais errantes, sempre vacilantes acerca das coisas, em contraste com a única "bem acabada verdade". Cf. Conjectures and Refutations, p. 11, 164 e segs. 
6 Teogonia, 720-25.

7 Il ada, VIII, 13-16; cf. Eneida, VI, 577.

8 Ver meu Conjectures and Refutations, 4. . ed. rev., p. 126 e segs., 138 e segs., 150 e segs., 413.

9 Teogonia, 720-725.

10 A descoberta, parece, é devida a Parm nides; ver fragmento B 14-15: Brilhante noite ela desliza em volta da terra com uma luz que lhe é emprestada; sempre olhando ansiosamente para os raios do sol.

11 Ver Alfred Tarski, Logic, Semantics, Metamathematics, trad. por J. H. Woodger, Oxford University Press, N. York, 1956. Expus o tema em diversos lugares; ver, por exemplo, meu Conjectures and Refutations, p. 223-225.

12 Ver Lee Whorf, Benjamin, Language, Thought, and Reality, ed. org. por John B. Carrol, MIT Press, Cambridge (Mass.), 1956.

13 Ver Quine, W. V. Word and Object, MIT Press, Cambridge (Mass.), 1960; e Ontological Relativity and Other Essays, Columbia University Press, N. York, 1969.

14 Cf. Kunn, T. S. "Reflections on my Critics", p. 232. In: Imre Lakatos e Alan Musgrave (Eds.). Criticism and the Growth of Knowledge, Cambridge University Press, Londres, 1970, p. 231-278 [Trad. brasileira: A Cr tica e o Desenvolvimento do Conhecimento, Cultrix/Edusp, S o Paulo, 1979].

15 Quando redigia esta seç o, tive originalmente em mente Thomas Kuhn e seu livro The Structure of Scientific Revolutions - Chicago University Press, Chicago, 1970. [Trad. brasileira: A estrutura das revoluç es cient ficas, Perspectiva, S o Paulo, 1978]. (Ver também minha contribuiç o, "Normal Science and its Dangers". In: Imre Lakatos e Alan Musgrave (Eds.). Criticism and the Growth of Knowledge, Cambridge University Press, Londres, 1970, p. 51-58.) Todavia, como Kuhn assinalou, essa interpretaç o baseou-se num mal entendimento de seus pontos de vista (ver seu "Reflections on my Critics". In: Lakatos \& Musgrave (Eds.). op. cit., p. 231-278; e seu "Postscript 1969" para a 2. ${ }^{a}$ ed. de The Structure of Scientific Revolutions), e estou inteiramente pronto a aceitar sua correç o. $\mathrm{N}$ o obstante, considero como muito influente o ponto de vista aqui discutido.

16 Para uma cr tica de Karl Mannheim, ver meu Open Society, vol. II, caps. 23 e 24. 
17 Poucas pessoas parecem ter entendido que através de sua equaç o $\mathrm{E}=$ $\mathrm{mc}^{2}$, Einstein ressuscitou a teoria do calor (calórico) como fluido, pela qual a quest o de saber se o calor tem peso era considerada crucial. De acordo com a teoria de Einstein, o calor tem peso - só que pesa muito pouco.

18 Cf. a discuss o entre Planck e Mach, especialmente o artigo de Planck "Zur Machschen Theorie der physikalischen Erkenntnis", Physikalische Zeitschrift, vol. 11 (1910): p. 1186-1190.

19 Ver, por exemplo, BeLl, J. S. "On the Einstein Podolsky Rosen Paradox", Physics, vol. 1 (1964), p. 195-200; Bell, J. S. "On the Problem of Hidden Variables in Quantum Mechanics", Reviews of Modern Physics, vol. 38 (1966), p. 447-452; Clauser, John F., Horne, Michael A., Shimony, Abner e Holt, Richard A. "Proposed Experiment to the Test Local Hidden Variable Theories", Physical Review Letters, October 13, 1969. Uma extens o ou reforço do paradoxo EPR, descrito em meu Logic of Scientific Discovery, Basic Books, N. York, 1959, p. 446-448, parece-me envolver uma refutaç o decisiva da interpretaç o de Copenhague, já que as duas medidas simult neas juntas admitiriam "reduç es" simult neas dos dois pacotes de ondas que n o podem ser empreendidas no interior da teoria. Ver também o recente artigo de James Park e Henry Magenau, "Simultaneous Measurability in Quantum Theory", International Journal of Theoretical Physics, vol. 1 (1968), p. 211-283. [Trad. brasileira: A L gica da Pesquisa Cient fica, Cultrix/Edusp, S o Paulo, 1974, p. 506-527; ver também cap. IX, p. 237-274].

20 Ver meu artigo "Quantum Mechanics Without 'The Observer' “. In: Mario Bunge (Ed.). Studies in the Foundations, Methodology and Philosophy of Science, vol. 2: Theory and Reality, Springer-Verlag, N. York, 1967.

21 Ver meu Open Society, vol. II, cap. 11, seç o II; ou meu ensaio "Quantum Mechanics Without 'The Observer' “, especialmente p. 11-15; ou meu Conjectures and Refutations, p. 19, 28, seç o (9) e p. 279, 402.

22 Estou muito agradecido a meu amigo Alan Musgrave por me lembrar de incluir neste artigo o diagnóstico lógico contido na presente seç 0 . 